\title{
Extrapolating Stem Cell Potential into Therapy: Current Parameters for Treating Neurological Defects
}

Kenyon S. Tweedell

Department of Biological Sciences, University of Notre Dame, IN 46556, USA

\begin{abstract}
Stem cell use in regenerative medicine has its basis on experimental procedures developed in animals. Several natural stem cells from embryos, fetal and adult tissues and induced pluripotent stem cells have evolved as choices to replace or repair one or more cell types in human maladies. The roles that stem cells serve as precursors is incumbent upon establishing their potential, reliability and efficacy before they are selected as therapeutic agents in humans with specific human diseases. A group of neurodegenerative diseases with related cell deficiencies, multiple sclerosis, amyotrophic lateral sclerosis, Huntington disease and Parkinson disease are reviewed at the current preclinical potential as prospects for stem cell therapy and compared to present clinical trials on human patients with degenerative diseases. Only a limited number of native stem cell sources have been utilized and early results indicate their safety and moderate effectiveness after transplantation. With continued preclinical research, the usefulness of induced pluripotent stem cells will expand the options.
\end{abstract}

Keywords: Stem cell therapy; Pluripotent stem cells; Neurodegenerative diseases

\section{Introduction}

Stem cell therapy has been applied to correct a number of deficiencies in human patients. The basis of treatment has been previous animal studies using a variety of stem precursors derived from embryonic stem cells, fetal and adult tissue specific stem cells and other broad spectrum stem cells, simulated and reprogrammed stem cells and induced pluripotent embryonic-like stem cells. Two avenues have been pursued generally, stem cell delivery by transplantation or activation of indigenous stem cells. Several reports have cautioned that a number of pre- and post operative issues need to be resolved before human clinical trials are pursued $[1,2]$. Here are examined the current status for several of the recommended preclinical key factors that are compared to current human clinical trials on a group of related neurological disorders. Adequate testing on animal models for specific diseases predicts the utility of cells for replacement, repair or protection of normal neuronal cells. Expedient data are sought such as preferred sources of stem cells and the many ubiquitous obstacles to further successful treatment such as the fidelity of cell differentiation and sustained integrity of engrafted cells, immunological rejection, ability to migrate and seek damaged cells. Clinical approaches may vary but tentative results that focus on the use of specific stem cells for functional neurons suggest there are some common protocol factors, transplantation procedures, safety, efficacy and permanence of action.

\section{Sources of stem cells}

Selection of the most efficient stem cell progenitor for human cell therapy is related to the specific deficient cell of the disease, and the ability to produce sufficient cell numbers of stable differentiated cells that can be transplanted safely. Some of the most eligible stem cells currently available for neurological therapy are considered here.

Embryonic: Embryonic stem cells were recognized when the (embryo) formative cells, an inner cell mass of early mouse blastocyst stage embryos were isolated and proved capable of differentiating into all of the adult specialized cells that form from the three inclusive embryonic germ layers. Consequently they were characterized as being pluripotent. Embryonic stem cell lines (ES) were derived that proved to be self-renewing and pluripotent, capable of producing secondary stem cells for all the specialized adult cell lineages. The ES cell lines expressed their full differentiation potential within embryonic bodies in vitro, developed benign teratomas of differentiated cells in immunodeficient mice and were capable of generating secondary stem cells for all of the adult cells. Extracellular signal regulators can destabilize the pluripotency of ES cells and when subjected to transcription factors and other agents, they can be directed to differentiate along specific cell lineages. Progenitor cells are produced that have a specific differentiation pathway with more stability but limited selfreplication such as neuronal cells. In cell culture, progenitor cells can be identified and isolated by FAC cell sorting [3] and expanded in culture for future use in therapeutic cell transplantation. Later, human pluripotent embryonic stem cell (hESC) lines were produced [4] and many new hESC lines followed. With similar properties they were cultured over feeder cell cultures and could be identified by cell surface markers, transcription factors, tests for pluripotency, [5]. Initially the establishment of these hESCs lines was labor intensive and inefficient. They produced ethical concerns from embryo destruction, showed chromosomal abnormalities in culture over time, often caused an immune response in other hosts and could elicit non-predictable interaction with the host after transplantation in vivo. Major advances in their initial isolation techniques have been made since then. Two more recent human embryonic stem cell lines were produced from frozen IVF embryos when they were thawed and developed to the blastocyst stage [6]. These isolates were grown on pathogen free human placental feeder cells under serum free condition thus reducing the

${ }^{*}$ Corresponding author: Kenyon S. Tweedell, Department Of Biological Sciences, University of Notre Dame, Notre Dame, IN 46556, USA, Tel: 574-6313-6624; Fax: 574-631-7413; E-mail: Tweedell.1@nd.edu

Received November 12, 2011; Accepted December 08, 2011; Published December 09, 2011

Citation: Tweedell KS (2011) Extrapolating Stem Cell Potential into Therapy: Current Parameters for Treating Neurological Defects. J Bioengineer \& Biomedical Sci S2:004. doi:10.4172/2155-9538.S2-004

Copyright: (c) 2011 Tweedell KS. This is an open-access article distributed unde the terms of the Creative Commons Attribution License, which permits unrestricted use, distribution, and reproduction in any medium, provided the original author and source are credited. 
introduction of protein contamination, They exhibited typical markers of "stemness" and could be differentiated in vitro and in vivo into cells from all three germ layers. A newer approach to retrieving embryonic stem cells relies on obtaining cells from early cleavage cell stages before formation of the blastocyst. In the mouse a single cell biopsy at the 8 cell stage yielded ES cells while the remaining blastomeres developed into a normal blastocyst capable of uterine implantation. Next, entire 8 cell stage human blastomeres were co-cultured in separated chambers that generated hESC cell lines [5]. Later five hESC lines were derived by biopsies of one or two blastomeres without cell co-culture, with comparable efficiency and expression of the same characteristics as previous lines from blastocyst embryos. Further, the donor embryos survived and continued to develop into blastocyst embryos [7]. Other biopsies of blastomeres have yielded hESC cell lines without prior embryo co-culture when grown on human foreskin fibroblasts [8]. These cultures produced ES stem cells with progeny in all three germ layers. At present, about $20 \mathrm{hES}$ cell lines have been established from biopsies of 8 cell to 32 cell stage embryos in the US and UK. While NIH had approved many new cell lines, the use of federal funds was blocked (May, 2011) but a recent court decision has approved the use of government funds for all types of hESC research [9].

Somatic stem cells: More restrictive stem cells have been recovered directly from fetal or adult organs and tissues. Some tissues harbor cell specific stem cells, i.e. satellite stem cells in striated muscle where they serve as reservoir stem sources for a unique progenitor cell type. Other stem cells are multipotent and capable of forming several different kinds of cells within a related developmental pathway such as neural stem cells. Neural stem cells are used for treatment of several neurodegenerative disorders. Many somatic stem cells are difficult to obtain and isolate as a renewable cell line. Such cells or their progeny may be limited further by host incompatibility if they are inserted into other individuals of the same (allogenic) species and require some form of immunosuppression. If possible, engraftment of stem cells recovered from the same individual are preferable and constitute an autologous transplant that is less likely to provoke a strong immunological response. When undifferentiated stem cells are introduced directly into a host, their developmental behavior is often non-predictable once they proliferate in vivo. Consequently, specific progenitor (developmentally secure) cells are usually utilized. Other somatic stem cells are more versatile, capable of forming several different kinds of cells in different cell lineages. Certain of these stem cell niches have been extensively investigated and utilized in animal and human systems; the most productive include stem cells recovered from the bone marrow. The major constituents of bone marrow are haematopoietic (HSC) stem cells, the source of all blood cells and cells of the immune system. Within the bone marrow derived cells, asubpopulation of stem cells, mesenchyme stem cells (MSCs) have been very productive as precursors for bone, cartilage, muscle and adipose tissue and neural cell promoters. These bone marrow, more specifically multipotent "stromal cells" are particularly useful since they have an anti-inflammatory effect and promote immuno-modulation by the release of growth factors and cytokines [10]. While best derived from bone marrow, they are also found in adipose tissue, connective tissue, umbilical cord and the placenta. Several studies on the mouse and rat indicated that bone marrow cells could be induced to differentiate into other progenitor cells such as muscle (myocytes), liver and neural cells [11] but the latter not without controversy. Adult bone marrow stromal cells were reported to differentiate into neural cells in vitro [12]. Subsequent work confirmed the migration of bone marrow stem cells (MSCs) into the human brain [13] where they exhibited neural cell markers [14]. Some question whether MSNs actually form neural cells [15] but that they may assist in neuronal development. The bone marrow derived HSC stem cell population does possess the ability to form neural stem cells. A sub-population of human (hHSCs), identified by surface antigen markers, CD34+ cells, form human neurons when transplanted into the chicken spinal cord [16].

Reprogramming somatic stem cells: The production of pluripotent stem cells can occur by reprogramming adult cells that can then serve as an autologous source of a stem cell. One method is to return a somatic cell nucleus back into a simulated embryonic state. The procedure, somatic cell nuclear transfer SCNT, involves removing a nucleus from an adult somatic cell and transplanting it into an egg (oocyte) that lacks its nucleus. As the cell develops, the resulting blastocyst embryo can be the source of cloned embryonic pluripotent stem cells that are duplicated in cell culture. When returned to the same individual, they are compatible with the autologous donor individual and capable of differentiating into specific stem cell lineages. The same result can be produced by the fusion of a somatic cell and the anuclear oocyte that results in a nuclear transfer (NT). The use of the SCNT technique to provide autologous human pluripotent stem cells for clinical use has not been too productive thus far due to lack of available oocytes, difficult isolation procedures and inefficiency producing a very low yield. Various other technical reasons and ethical concerns led to a search for new sources of pluripotent stem cell lines. These included the covery of SCNT stem cells from developmentally arrested embryos, recovery of cells from the epiblast of post-implantation embryos, the production of ES cell lines from nonfertilized eggs ( parthenote stem cells), the induction of stem cell-somatic cell hybrids by direct cell fusion and most recently induced pluripotent stem cells from somatic cells [5].

Parthenogenetic stem cells: Some early reports indicated that parthenotes (egg activation without fertilization) resulted in development to the blastocyst stage and beyond but are incapable of developing into viable embryos. Human oocytes left over from in vitro fertilization ( IVF) procedures can be activated and such haploid embryos are developed to the blastocyst stage when ES cells are taken. This has resulted in the production of four human parthenogenetic cell lines (phESC). Such embryos express human ES cell markers, have a normal karyotype, form embryoid bodies, teratoma formation and derivatives of the three primary germ layers [17]. Genotyping indicated that all four lines were homogenous for HL antigens in the major histocompatibility complex (MHC). Ultimately these cell lines could be installed in stem cell banks where the closest immunological match could be sought. In addition to host compatibility there are many practical conditions that need to be resolved, their performance after engraftment, possible genetic instability (aneuploidy) and oocyte stability.

Induced pluripotent stem cells: A new method of producing pluripotent stem cells evolved that directly reprogrammed partially or fully differentiated somatic cells into embryonic-like stem cells with pluripotent capabilities. Pioneered by Takahashi and Yamanaka [18] mouse fibroblasts were exposed to an excess of selected transcription factors (Oct4, Sox2, cMyc and Klf4) and then integrated into the genome by a virus. This reprogrammed the fibroblast genome back to an embryonic-like state. These cells could mimic the differentiation potential and had the characteristics of embryonic (ES) stem cells. Moreover, transplantation of such induced pluripotent stem cells (iPSCs) back into the same individual are autologous implants with minimal immune response. Different combinations of transcription 
factors and delivery agents also produced similar human iPS cells (hiPS). The cells share similar characteristics, cell surface markers, developmental embryonic bodies, as with ES cell lines [5]. Next Takahashi and colleagues generated iPSCs from adult human dermal fibroblasts (HDF) with the same factors used in mice, Oct3/4, SOX2, Klfx and c-Myc using retroviral transduction [19]. Afterwards, the retroviruses were silenced which suggested continual expression of the transgenes was not needed to maintain the iPS cells. Similar fibroblasts from several sources, fetal, neonatal and cells from adult human skin have yielded iPS cells with the same induction factors [20]. Oct 4 and Sox 2 were found to be essential and the addition of either Klf4 or Myc enhanced the efficiency. The iPS cells could either form chimeric embryos by fusion with a normal blastocyst and xenografts of the induced hiPS cells in mice produced benign teratomas composed of cells from all three germ layers. The hiPS cells from fetal and adult skin fibroblasts also resembled ES cells in their gene expression.Human foreskin fibroblasts were also used to produce iPSC presumably free of both vectors and transgene sequences. A non-integrating episomal vector (Epstein-Barr nuclear antigen-1) was employed along with Oct4, SOX2, Nanog, and LIN 28 (a pluripotency mRNA binding factor). Other factors were added to increase efficiency of cell yield. It was reported that removal of the episome afterwards produced iPS cells free of the vector and transgene sequences. The hiPS cells from fetal and adult skin fibroblasts resembled ES cells in gene expression and formed teratomas in immune deficient mice [21]. Also, the use of non-viral alternatives such as plasmids or the piggyBac transposon to deliver transcription factors have eliminated changes in the genome since the transgenes can be removed readily [22].

RNA induced pluripotent cells (RiPSC): A recent and more refined method of inducing pluripotency in somatic cells that is even more efficient and faster came from creating slightly modified synthetic RNA molecules and inserting them into somatic cells. In this experiment, fibroblasts were transfected with a synthetic RNA plus an interferon inhibitor. The cells fail to recognize the slightly modified synthetic RNA and make a new protein that initiates reprogramming causing them to dedifferentiate into RNA induced pluripotent embryonic-like stem cells. Subsequently, the foreign RNA breaks down and the reprogrammed cells maintain their genetic identity [23]. In a separate approach RiPSCs were produced with the introduction of mRNA from four transcription factors in vitro. The mRNA was synthesized from cDNA of the transcription factors for Oct4, Lin 28, SOX2 and Nanog. Fibroblasts derived from foreskin were transfected with a plasmid (pTMA) for five consecutive treatments continuously to activate the pluripotent genes. Later the transfected RNA was removed [24]. Since this technique is just evolving, it is too early to assess its application at the pre-clinical level but promises to be a very significant approach to clinical treatment using RiPSCs in many diseases without the introduction of DNA and potential changes in the cell genome.

\section{Direct reprogramming (Transdifferentiation)}

Still another approach toward producing autologous induced neural stem cells has been the report of Vierbuchen et al. [25] who were able to directly convert fibroblasts into functional neurons without prior induction of the pluripotent state. They reported the direct conversion of mouse embryonic and post-natal fibroblasts in vitro into neurons (iN) with neuronal lineage transcription factors, Ascli, Brn2 and Mytil within a week. Later the same 3 factors were able to produce functional neurons from human ES cells [26]. When another transcription agent, Neuro D1 was added to the above factors, they could generate human iN cells with neuronal functions directly from fetal and postnatal human fibroblasts. Presumably this event was trans-differentiation of human somatic cells, although cell fusion remains a possibility. This procedure could add another approach to neurological disease studies. It may be noted that Brain $2(\mathrm{BRn} 2)$ also interacts with Jab1, a gene involved in the onset of Parkinson's and Alzheimer's disease.

\section{Preclinical Investigations with Stem Cells}

Each of the above methods for producing stem cells have their potential application for clinical therapy and are constantly being improved in the research laboratory. While a myriad of pre-clinical studies have come from studies in animals and on human stem cells, the choice of a particular source of stem cells is critical and usually tailored to the malady or disease being confronted. A prophetic assessment of the strategies for the use of human stem cells in the treatment of neurological disorders has been outlined by Lindvall and Kokaia [27]. Recruitment of stem cells may be from embryonic (ESC) stem cells, fetal or neonatal derived neural stem cells (NSC) or neural precursor cells derived from the adult CNS, and MSCs and HSCs from bone marrow and other sources. While withdrawal of differentiation inhibitors leads to spontaneous differentiation of ES cells, if no other extrinsic components are added, they differentiate into primitive neural stem cell [28]. An initial study on the differentiation potential in six human ES cell lines was conducted without fetal calf serum, retinoic acid and no feeder cells. The cells progressed along a differentiation pathway into neuroepithelial cells expressing nestin, Sox 1 and Pax 6. Further differentiation led to the formation of radial glial cells that expressed vimentin and glial cell factors GLAST and GFAP. The terminal stage led to GABA neurons and glutamate neuron formation [29]. A second protocol for stepwise progression of neural stem cells from approved hESC lines has been established using a low level density mouse embryonic fibroblast feeder cells [2]. The undifferentiated pluripotent hESC cells progressed into neuroepithelial cells. These continued to develop into neural stem cells which became migrating neurons ending in the formation of mature neurons. Questions still remain on what controls the development into each distinct cell type. A number of growth factors/cytokines regulate the differentiation of neuronal precursors from ES cells in the mouse. These include the leukemia inhibitor factor (LIF), the fibroblast growth factors (FGF), the platelet derived growth factor (PDGF), nerve growth factors, NGF, glial cell neurotroptic factor, GDNF and others. The regulatory sequence for the transition of neural cells from ES cells currently proposed by $\mathrm{Hsu}[30]$ is initiation of neural stem cells (NSC) by default followed by the following sequence: NSCs $>$ Neuronal Progenitor Cells $>$ Glial Progenitor Cells (or) Neuronal Progenitor Cells $>$ Adult Cells. The NSCs in the presence of FGF1, 2 either form more self-renewing NSCs or produce neural progenitors. When Neural Progenitors are exposed to GDNF and other factors, glial progenitors form. Other neurotrophic factors, NTF/LIF, promote further differentiation into astrocytes or in the presence of T3 they differentiate into oligodendrocytes. Alternatively, if neural progenitors are exposed to Brain NGF and other neurotrophic factors they ultimately form adult neurons by means of PDGF. In most of these cases additional preparations, progenitor cell differentiation or genetic changes can be applied to the stem cells to enhance the formation of specific neurons or glial cells after transplantation into the CNS. Of prime importance to neuronal stem cell therapy is the guidance of engrafted exogenous neural precursors during migration. Neuronal stem cells were isolated directly from the brain (diencephalon) of a 10.5 week old human embryo [31]. Stable multipotent stem cell lines were established which were renewable and could form several progenitor neural cells. When growth factors were removed, the stem cells differentiated spontaneously. Each progenitor cell type was established 
by clonal analysis either into astrocytes (expressing glial fibrillary acidic protein) oligodendrocytes (expressing galactocerebroside) and neurons ( $\beta$ tubulin). The stable human stem cell derived neural and glial progeny could be engrafted successfully into the adult rodent brain providing a proof of principle for future human therapy. The problem of the most appropriate therapeutic strategy for humans has been recently addressed by Ronaghi and colleagues [32] as they analyzed the comparative use of embryonic stem cells, endogenous neural stem cells (NSC) or induced pluripotent cells (iPS) for treatment of the specific traumatic events such as spinal cord injuries. They found that the use of ESCs have the advantage since they can produce neural progenitor cells (NPCs) that can develop regional specific neurons but need further preclinical studies on the integrity of the cell populations. The cells may form benign teratomas after inoculation and require continued studies on their differentiation traits in animal models. Multipotent endogenous neural stem cells obtained from the human spinal cord have less tendency to form tumors but also need more cell culture refinement and better survival rates after transplantation into the patients. The potential application iPS vs ES cells for clinical therapy has been assessed recently [33]. Since ES cells and iPS cells share many characteristics, emphasis has been upon comparing the likenesses and differences of these two sources. One distinguishing feature of iPSCs derived from mouse and human somatic cells was that the degree of their differentiation potential varied and was relative to their cellular origins. The iPSCs have an epigenetic memory that designates a favored status for choosing a particular cell lineage. The amount of methylation levels in the histone associated chromatin is one factor [34]. A comparison of native ES cells, both blood and fibroblast derived iPSCs and SCNT cells showed that the influence of epigenetic methylation of DNA was highest in cells derived from iPSCs while SCNT cells fingerprints were closer to somatic cells obtained from ES cells. Furthermore, when iPSCs are derived from fibroblasts, they are more likely to form bone cells while blood cells more likely arise from haematopoietic cells, i.e. they have a residual memory of their source. The procedure is very inefficient (between $0.001 \%$ and $1 \%$ ) and slow. Since the reprogrammed cells often retain copies of the inserted genes, there is also a tendency for them to produce tumors. Other similarities/ differences of iPS and ES cells were assessed by Amabile and Meissner [35] who noted that iPS cells are not identical to ES cells. Both types of pluripotent cells may have chromosomal changes in long term cultures. Established hiPS cell lines express key markers of ES cells but the global gene expression profiles varied. Several neural and epidermal genes are up regulated early in reprogramming, many self-renewal genes are reactivated but pluripotency genes vary which further suggested that iPS cells are not identical to ES cells. Yet the epigenetic state of iPS cells is very similar to ES cells. Evaluation of the developmental potential in the mouse have a variety of tests including the valued tetraploidembryo complementation test. In the human iPS cells, only in vitro differentiation and teratoma formation are available prior to clinical testing which emphasizes the need to examine the epigenetic and transcriptional state of the iPS cells.

\section{Neural Cells from Induced Pluripotent Cells}

The use of iPS cells as a source of different types of NPCs, neurons or glial cells confirms teratoma formation, can be made free of vector and transgenic sequences but may exhibit deviations in cell programming [21]. The neural differentiation sequence of ESCs and iPSCs is very similar as they both utilize the same pathway to form neuro epithelial and succeeding neural types. Neural cell lines derived from either embryonic hES or iPS cells continue to vary in their productiveness. Each source of cells can differentiate into neurons and glial cells, expressing the same genes but more than $90 \%$ of the hES cells produce neural cells while iPS cells are much more variable in their response to differentiation stimuli [36]. Recently several caveats have been raised about the potential use of iPSCs as a substitute cell source for embryonic or somatic stem cell application in cell engraftment clinical therapy. Variations in karyotypic stability and unpredictable deviations in cell differentiation were noted [37]. They were reported as differing from hES stem cells in their epigenetic profile, ability to proliferate and cellular senescence and apoptosis of cell progeny [38] along with gross chromosomal changes, induced mutations and other aberrations in DNA arrangement including single DNA bases $[39,40]$. Another concern is the revelation that transplantation of mouse autologous iPS cells obtained from reprogrammed fetal fibroblasts can cause an immune response in genetically matched mice [41]. Using a mouse model that normally allows teratoma formation with matched ES cells, the reprogrammed iPS cells, produced either by viral or episomal methods, result in an immune reaction when transplanted back into genetically matched mice. Evaluation of the results [42] suggests these results may be caused by epigenetic or genetic abnormalities or possibly selection of other somatic cells may provide different reactions. Likewise, if progenitor cells or fully differentiated progeny of the iPSCs were used, the results could differ. Lastly, they suggest that tests of human iPSCs be conducted in animal models before use in clinical therapy At present, six pluripotent cell lines from human somatic fibroblasts [35] plus isolates from blood cells, neural cells and keratinocytes have been derived after delivery of transcription factors, using Oct4, Sox 2 and usually c-myc and Klf 4 [33]. The major contributions of iPSCs has been their utilization as a platform to study individual diseases and for screening potential drugs [21]. The isolation of cells from patients with specific genetic diseases has been a source of many specialized iPS cell lines. Each disease related isolation has shared a large number of pluripotency genes with each other. An extensive list of better known diseases includes Parkinson disease, Huntington disease, types of muscular dystrophy, diabetes, and a variety of lesser known diseases have yielded individual cell lines [20]. Such investigations have also permitted a comparison of the normal vs.disease related molecular changes and serve as a means to develop drugs in the treatment of a disease. For example, skin fibroblasts from a human patient with spinal muscular atrophy led to the establishment of the defective motor neurons in culture that revealed specific defects in the neurons [43]. Fibroblasts from patients with Parkinson disease were isolated, reprogrammed and then selectively differentiated into dopaminergic neurons [44]. Such cell lines are extremely useful for developing treatment procedures. At this point, human iPSCs still lag behind ES cells as a source of stem cells for clinical therapy. Responses to differentiation signals vary in different isolates, possibly due to incomplete reprogramming. Before any of the neural stem sources can be safely applied in human stem cell therapy several other issues need to be considered. Once a specific stem cell line is selected and established, the integrity of the cell line must be verified, i.e., the ability to maintain self renewal and retain the original or derived pluripotential ability.

\section{Cell Migration}

In addition to introducing exogenous stem cells into patients with a neuro-degenerative disease, a second stem cell strategy has been to recruit endogenous stem cells and direct them to the affected areas of the brain or spinal cord to produce new cells as well as correct defects. Migration promoting proteins fibronectin and laminins interact with cell surfaces and the ECM. Directed migration likely relies on cues from the microenvironment. Some say that patterns of growth factors in the 
ECM may help direct cell migration to the wound site [45]. A study on temporal lobe epilepsy in mice indicates that ES derived neural progenitors show a chemotactic response to the chemokine CXCL12 both in vivo and in vitro [46] and suggest it may direct migration of neural progenitors to specific regions in the adult brain hippocampus. A particular useful ability of mesenchymal stem cells is their ability to migrate to sites of injury [47] mentioned later in clinical trials for MS and HD.

\section{Human Clinical Trials}

The U.S. National Institutes of Health has established a registry for human clinical trials on human diseases conducted within the United States and around the world including those addressed here on neurodegenerative diseases [48]. Details on the description of each study, includes stem cells transplants, pretreatment, kinds of intervention, drugs, patients recruited etc. can be pursued after entering the separate diseases on the NIH web-page. Individual studies can be retrieved by titles, sponsor, and the collaborator study site. The time of initiation and predicted completion dates may be obtained. Clinical investigations on the therapeutic use of human stem cells in clinical therapy are classified by evolving standards of treatment. Such studies are designated as Phase I, emphasizing safety, dosage, side effects and feasibility in a small group, Phase II adds effectiveness in a larger group, Phase III examines side effects, safety, and comparison to other treatments that are tested in larger groups of people and Phase IV, adds approval of drugs by US Food and Drug administration and the side effects of treatment over long term use in various populations.

\section{Neurodegenerative Diseases}

A group of neurodegenerative diseases of the Central Nervous System share similar characteristics and clinical tests using stem cell therapy are often related. Currently, a clinical trial is being conducted to develop human iPS cell cultures from skin biopsies of patient's hair. The donors are patients from ten different neurodegenerative disorders. Started in 2009, it is conducted by Reubinoff at the Hadassah Medical organization in Israel [48]. The purpose is to acquire a bank of iPS cell lines for the study of individual diseases and for screening new drugs.Stem cell therapy in certain of these diseases is directed toward cellular replacement, cell repair and provision of neurotrophic factors such as in amyotrophic lateral sclerosis and Parkinson's disease. Neuroprotection and cellular repair are prime objectives in MS followed by modulation of the immune system. Several of the neurodegenerative diseases of the brain share commonalities and thus share the use of MSCs in the approach to cell therapy. This include multiple sclerosis, ALS and Parkinson's disease. The major impact of MSCs after transplantation is the promotion of growth and repair of endogenous neurons, reestablishing synaptic connections between damaged neurons, the regulation of inflammation an decreasing apoptosis. This is accomplished by providing trophic factors such as brain derived growth factor (BDNT) and glial derived growth factor (GDGF) [47].

\section{Multiple Sclerosis (MS)}

This is the most prevalent neurodegenerative disease. MS affects the myelin sheath of neurons in the brain, spinal cord and the optic cranial nerve. The myelin sheath (white matter) is gradually destroyed causing injury to nerve axons. Destruction of the oligodendrocytes (myelin producers) takes place also. Normal attempts to repair the myelin coating causes multiple scars (scleroses) on the myelinated nerve axons of the central nervous system. The effect is an inflammatory autoimmune response to normal neuronal elements, the myelin sheath or its cellular source, the oligodendrocytes. MS is believed to be initiated by infective agents, viruses, bacteria or stress in genetically susceptible individuals. These events result in several symptoms beginning with impairment of eyesight, blurred or double vision, general muscle weakness, lack of coordination and balance. Abnormal sensory perceptions, prickling, numbness, etc. along with slurred speech, tremors and dizziness may occur. Other changes in cognition, concentration, memory and depression can follow. Several drugs are available for treatment, many involving components for immuno-suppression such as interferons and Novantrone, along with Capaxone, a myelin basic protein and specific antibodies that reduce the frequency of attacks (see US Lib. Med: Pub Med Health 2011). A method for rating the relative disability from MS developed by Kurtzke is the Expanded Disability Status Scale (EDSS) in steps from 1 to 10 . The score is based on testing and examining the central nervous system's control of human activity (bodily functions). A score of 1 is no apparent disability and 10 is a complete breakdown. The majority of patients have relapsing MS, characterized by short periods of remission between progressive phases of the disease. Another type is secondary progressive MS, a relapse after the first symptoms, that changes and worsens progressively. A more severe condition is a primary progressive state where MS continues to decline immediately after its initiation. Several types of stem cells are being used in preliminary trials to treat this disease. Some were designated to correct or replace the immune system while other stem cells were directed toward replacing the damaged myelin sheath or the myelin producers, the oligodendrocytes themselves. A recent comprehensive review on stem cell transplantation and the results of an international group of scientists of the Multiple Sclerosis (STEMS) group has outlined the ground rules for current MS research. The major objective of present clinical therapy is neuroprotection. This is projected by reducing inflammation through immunomodulatory intervention and repair to the nervous system by inducing remylelination and rescue of the neurons [49]. The two major stem cell sources are neural stem/ precursor stem cells (NPCs) preferably recovered from fetal tissues. They support immunomodulation and indirectly affect remyelination. The second source consists of stem cells originally obtained from bone marrow, that principally affect immunomodulation. These are haematopoietic stem cells (HSCs) and mesenchymal stem cells (MSCs). The NPCs are generally delivered by intrathecal injection (the sub-arachnoid space beneath spinal cord and brain membranes) while the MSCs are most successful via intravenous injection. The immediate action of either stem cell therapy is still unsettled. In culture NPCs are capable of forming neurons, oliogodendrocytes and astrocytes. They might provide cell replacement but more likely produce a "spin off," a neurotrophic effect, resulting from the release of cytokines, chemokines and integrins that affect remyelination while the MSCs have an antiinflammatory effect. A subset of multipotent (HSCs) identified by their surface antigen CD34+ is capable of developing into glial cells and myelin producing oligodendrocytes as well.

\section{Clinical trials}

The results of early clinical trials on MS therapy began with haematopoietic derived stem cells. Transplantation of autologous HSCs from bone marrow or peripheral blood was conducted in Europe on 85 patients with advanced MS. At a median period follow up (16 months) in the trial, neurological improvement was seen in 18 patients while confirmed disease progression was seen in 22 individuals. At the end of 3 years, $74(+/-12) \%$ of the patients had survived with no further progression of the disease (related to the initial disease stage ). They also found that a small group receiving autologous HSCs can regenerate 
a tolerant immune system. The results suggested that the management of progressive MS is possible but with significant mortality [50]. Another preliminary investigation on three MS patients utilized mesenchymal stem cells (MSCs) derived from a stromal cell fraction obtained from adipose tissue. Many other cell types are found in this tissue fraction. All 3 patients showed improvement in diverse symptoms of MS and suggested such cells may be worthy of trial investigations [51]. A feasability evaluation for the injection of MSCs into MS patients and an effort to prevent further neurodegeneration was implemented in several phase I/II clinical trials [48]. Karussis et al. [52] at the Hadassah Medical Organization injected bone marrow MSCs both intrathecally and intravenously. Initially 10 patients with MS (and 10 with amyotrophic lateral sclerosis) were treated. The early results indicated that both types of stem cell inoculations are feasible and safe. A projected second phase of the ongoing investigation is designed to further evaluate the safety and feasibility of the MSC injections into MS patients and to measure the migratory ability of these cells. The MSCs were tagged with super-paramagnetic iron oxide particles (FDA approved) to determine their position after detection by MRI of the brain and spinal cord. The patients were evaluated by changes in the EDSS rating scale and the MRI data used to evaluate lesions in the brain. The study is still in progress. Another neuroprotective therapy investigation for MS by Chandran at the U. Of Cambridge utilized autologous bone marrow derived human (hMSC) stem cells. The stem cells were injected intravenously ( 2 million cells) with the primary intent to measure the efficacy and detect adverse reactions. Secondarily, the efficacy of the same dosage on visual functions was designed as a strategy for testing neuroprotective agents, the sentinal lesion approach. Pre and post vision effects were monitored by clinical, neurophysiological and imaging assessments. A progress report [53] was published in 2011. It was based on 10 participants with secondary progressive MS, nine of whom had clinical optic neuritis. There were also 8 non-treated control individuals. The results showed overall the feasability and safety of MSC therapy. Secondarily, optic nerve-based measurements indicated significant differences between patients and controls. Using pre and post trial measurements, they assessed deficits in the anterior visual pathway. They proposed that these measurements can serve as a model for the wider aspects of the MS disease. A number of current clinical trials have been implemented, each with variations in the protocol [48]. One trial at the Fundacion Progreso y Salud in Spain by Fernandez and Ayuso is testing whether intravenous infusion of autologous MSC cells recovered from adipose tissue is effective in patients with secondary progressive MS. A second trial at the Case Medical Center in Ohio by Cohen expanded the numbers of autologous MSC stem cells in culture up to two million before a single intravenous infusion made into patients with relapsing MS. A third trial at the Royan Institute in Iran delivered autologous bone marrow MSC stem cells to one group of MS patients and compared the effect with injections of the cell free media into another control cohort. In a study at the Hospital Clinic of Barcelona, Spain by A. Saiz, an initial autologous MSC infusion into MS patients was followed by a reverse injection at 6 months of the cell medium only. A separate randomized double blind, cross over study compared the stem cell treatment with injection of just the suspension medium into active MS patients. A treatment of MS patients with both progressive MS and Neuromyelitis Optica (NO) was implemented by Xu Yun at the Nanjiig University Medical College, China. MSCs will be recovered from the umbilical cord and transplanted into MS patients. The trial proposes to measure the safety status and EDSS scores for MS, along with the visual evoked potential, brainstem auditory potential, somatosensory evoked potential and brain magnetic resonance imaging for NO. A different strategy for treating this autoimmune disease relies on replacing the reactive autoimmune system using chemotherapy and/or irradiation prior to reinstating it with appropriate (rescue) stem cells. This aggressive approach in a Phase I study was started in 1997 by R. Nash at the Fred Hutchinson cancer research center that utilized high dose immuno-therapy with total body irradiation, combined with antithymocyte globulin, prednisone and G-CSF (granulocyte colony stimulating factor). This was followed with transplantation of CD34+ cells recovered from autologous peripheral blood stem cells ( PBSC) into severe MS patients. A separate group of MS patients were submitted to the same regimen and implanted with PBSCs collected from syngeneic donors. An interim report was made on 26 patients in 2003 [54]. An estimate of patient survival after 3 years was $91 \%$. During the same period there was a progression of the disease based on the EDSS scale in $27 \%$ of the patients. An engraftment syndrome was noted in 13 of the first 18 individuals treated characterized by noninfectious fever sometimes with a rash. Three others had more severe neurological deterioration. The study has been completed but no further results have been posted. The effectiveness of immunotherapy with high dose cyclophosphamide and total body irradiation before injecting $\mathrm{T}$ lymphocyte depleted autologous peripheral blood stem cells (PBSC) or bone marrow stem cells (HSC) has been completed by Burt et al. at Northwestern Memorial hospital. Initiated in 2001 the recipient MS patients received cyclophosphamide IV, then filgrastim until PBSC harvesting was completed. The harvested cells or bone marrow then underwent T-lymphocyte depletion. Prior to cell infusion, patients received cyclophosphamide and methylprednisolone (antiinflammatory agent) as aids to the total effectiveness in halting disease progression, followed by total body irradiation. They then were infused with the treated PBSCs or bone marrow cells. A progress report for 21 patients in the relapsing-remitting phase of MS was released in 2009 [55]. After 3 years, $81 \%$ of the patients who had received HSC transplantation showed stabilization (no progression of disease) or slight improvement by 1 point on the EDSS scale. A control group was not included and a final report is pending. Another phase III trial initiated in 2006 by Burt at Northwestern hospital and the U. Of Sao Paulo, Brazil was designed to test the hypothesis that progression of MS immune demyelination disease may be related to axonal atrophy more than to immune mediated demyelination of neurons The treatment utilized haematopoietic stem cells obtained from cord blood using unmanipulated autologous peripheral stem cell therapy (PSCT) given to MS patients failing interferon therapy. The treatment was given along with cyclophosphamide and rabbit anti-thymocyte globulin (rATG) to counteract rejection of the stem cells by the body. Patients were those with early stages of relapsing-remitting MS. After recovery of the patients' stem cells, the immune system was destroyed by chemotherapy, then followed by engraftment of lymphocyte depleted HSCs. . This regimen was compared to a parallel trial that only used standard agents, interferon, Copaxone or Mitoxantrone on patients with relapsing inflammatory MS. The target completion date for this study is 2012. A similar but not as aggressive study on the mechanism of immuno-ablation was sponsored by the Nat. Inst. of Neurological Diseases and Stroke and conducted by Burt (N.W.U.) and Kerr (J Hopkins U.). Initiated in 2002 on secondary progressive MS patients, it was designed to eliminate myelin-reactive T cells from the MS patients, presumably previously activated, using immuno-ablation. The purpose was to determine if HSC therapy or immuno-ablation without stem cell rescue were most beneficial after the removal of myelin reactive $\mathrm{T}$ cells. Patients either received cyclophosphamide and an antibody Campath-1 followed by reconstitution with autologous haematopoietic stem cell transplants, similar to autologous bone marrow transplantation, while 
others were given a high dose of cyclophosphamide without stem cell rescue. The trial ended in 2011 and results are pending. A new 3 year study at the Ottawa Hospital Res. Institute of Canada also employed immuno-ablation with cyclophosphamide coupled to recombinate human GCSF. The autologous CD34+ selected cell replacements were given further conditioning with cyclophosphamide, bisulphan (alkylating agent) and rATG before transplantation of CD34 cells. A separate control group was treated with standard drug therapy. The target date is 2012. A slightly different approach for treatment of RR MS patients was conducted by Ildstad, Herzig and Kirzinger at the U. Of Louiville Brown cancer center. The engrafted cells consisted of allogeneic haematopoietic stem cells from bone marrow. The intent was to leave the patient's immune system intact, remove graft versus host disease cells from the transplant but retain tolerance-promoting facilitating cells. In this study, the host bone marrow system was joined with the engrafted bone marrow- facilitating cells, a mixed cell chimera. The dosage was gradually increased over the 3 year treatment period. The study was completed in 2010 but results have not been released.

\section{Amyotrophic Lateral Sclerosis (ALS)}

ALS is a neurodegenerative disease that causes degeneration of the motor neurons clustered in nuclei of the brain motor cortex and in nerve tracts of the spinal cord. In this disease degeneration of the motor neurons occurs in the cortico-spinal tract located in the anterior (lateral) horns of the spinal cord. In addition, non-neuronal glial cells contribute to neuronal inactivation and death [56]. These tracts undergo hardening (sclerosis) by scars left from phagocytosis of dying neurons by the glial cells located on peripheral motor nerves. Muscle atrophy is a secondary effect. As the nerves atrophy progressively, the muscles weaken and paralysis ensues. Originally cited as Charcot's sclerosis, it is also known as Lou Gehrig's disease that often presents itself initially on one side and results in muscle weakness which spreads systemically leading to paralysis and ultimately death. Greater than $90 \%$ of the victims arise randomly possibly from interaction of genetic and environmental causes [57]. About $25 \%$ of the cases are familial and five major genes have been identified (NIH News). Just recently a joint effort at NIH's National Institute on Aging by Traynor involving an international collaboration and a separate study at the Mayo Clinic in Florida by Rademaker have identified a single mutation of a gene on chromosome 9 that causes an extended repeat of a hexanucleotide. The single mutation has been found in $23 \%$ of familial samples from ALS patients. The same gene overlaps with a similar disease known as frontotemporal dementia [58]. Induced pluripotent stem cells have been produced from the fibroblasts of two patients with the familial form of ALS who also possessed an SOD1 gene. Fibroblasts obtained from the skin of the patients were submitted to four transgenes: KLFL, Sox2, Oct 4 and cMyc with a pseudotyped Maloney-based retrovirus. Several cell lines resulted and formed embryoid bodies (also associated with ES derived cell lines and other iPS cells). The iPS cells were differentiated into motor neurons in vitro after treatment with an agonist to the sonic hedgehog signaling pathway and retinoic acid. Several familial patient specific (autologous) iPS cell lines have resulted. Furthermore, these cells have been differentiated into cells that possess motor neuron markers [59]. The authors note that the iPS derived neurons are not presently suitable for clinical therapy until the oncogenic genes and retroviruses are eliminated and the need to identify and correct intrinsic defects in the neurons and glial cells.

\section{Clinical trials}

Some early clinical trials (PhaseI) in 2001 and later in 2007 in
Italy were conducted using autologous MSCs recovered from ALS patients by Mazzini and colleagues [60]. The trials were approved by a regional Ethical Committee and the (Italian) National Institute of Health. After cell expansion in vitro the autologous cells were placed in autologous cerebrospinal fluid and transplanted into the spinal cord at the thoracic level. There were no transplant related adverse events detected after clinical and radiographic examination. Furthermore, magnetic resonance (MRI) showed no damage to the brain or spinal cord, no tumor formation and established in principal the feasibility of this approach. In addition to their anti-inflammatory effect and immuno-suppressive effect, the MSCs have an anti-proliferative effect on microglial cells resulting in neuroprotection [10]. The direct replacement of damaged neurons has been sought using stem cell precursors, primarily MSC stem cells. New clinical trials [48] have focused on safety and efficacy of treating ALS patients with stem cells obtained from bone marrow with variations in technique. Two successive clinical investigations have resulted by Jimenez at the Fundacion para la Formacion e Investigacion Sanitarias de la Region de Murcia, Spain. Autologous stem cells were collected by laminectomy. The mononuclear cells from the bone marrow were separated with a ficol gradient and then delivered into AML patients by intraspinal infusion. The first study found the procedure to be feasible and safe. A fellow-up trial in 2010 is designed to repeat the same procedure using intrathecal infusion of the stem cells. A separate group will be given saline by the same route. Another efficacy study to determine the safety and methodology of using bone marrow cells was started in 2010 by TCA Cellular Therapy in Louisiana and directed by G. Lasala. A single infusion of autologous bone marrow stem cells was made by intrathecal delivery of the cells into six patients with moderate to severe ALS. The intent was to evaluate the safety of the infusion procedure. A similar trail using MSCs recovered from bone marrow is sponsored by Corestem and conducted by S.H. Kim at Hanyang Universitiy in Seoul, Korea. Intrathecal transplantation of stem cells into 7 patients will be assessed against a 64 non-operative control group. A different stem cell source and delivery site using MSCs isolated by subcutaneous biopsy of autologous adipose tissue is underway at the Mayo Clinic in Minnesota by Windebank. The cells were injected by lumbar puncture directly into the cerebral spinal fluid of one patient. All of these trials are in progress. Cultured neural stem were selected for the first FDH approved trial in the U.S. on stem treatment of ALS patients was initiated in early 2009. Fetal neural stem cells were obtained from the spinal cord of a donated 8 week fetus. The Phase I trial is directed by E.Feldman at the U. Of Michigan Medical School and performed at Emory University by Drs. Glass and Boulis. The cells were cultured by Neuralstem Co. and are capable of producing neurons and glial cells. The procedure allows five to ten human neural stem cell injections into the gray matter of the lumbar spinal cord region of 12 patients and up to a total of 18 (Emory U. website). The immediate aim is to establish the safety and feasibility of direct spinal cord injection of hNSCs into ALS patients in the early (walking) stage and later (non-walking) stage of the disease. The ultimate goal is to provide evidence for replacement of damaged neurons with functional neurons. The effects of the injections are being monitored by MRI of the brain and spinal cord. Early results of the first six patients who had lost mobility indicated no adverse effects and confirmed the feasibility and safety of the procedure. The next group of six will be patients with earlier stages of the disease and the last group will be given injections into the cervical region ( E. Feldman, American Academy of Neurology Annual Meeting April 12, 2011).

\section{Huntington Disease (HD)}

This is a fatal inherited disease with a defective gene that leads 
to progressive degeneration of medium spiny motor neurons (gabaminergic) in the striatum of the brain, as well as other neurons in the brain cortex and elsewhere. Changes in cell morphology result in a loss of medium spiny neurons and disruption of cell synapses [61] and is associated with toxic protein deposits in the neural cells. It is caused by a mutation in the huntingtin gene ( $\mathrm{Htt})$ located on chromosome 4 and usually occurs late in the reproductive life that results in the degeneration of basal ganglia located throughout the brain, brainstem and spinal cord [62]. The nerve degeneration results in uncontrolled writhing movements (Huntington's chorea) and the disease has three main spheres of symptoms: loss of motor functions controlling the musculature resulting in abnormal, involuntary movement (chorea) and involuntary spastic contraction of muscles (dystonia), and secondly, psychiatric behavioral changes in personality: mood swings, irritability, passivity, depression and anger and lastly decreases in cognitive function leading to dementia and death (National Institute Neurological Disorders and Stroke, NIH).

There are three basic approaches for HD therapy that focus on alleviating the symptoms of HD: 1 . The use of fetal cells or stem cell transplantation as a replacement for the degenerated neurons, 2 . the activation and manipulation of endogenous stem cells including neurogenesis in situ and 3. the delivery of neurotropic factors to protect extant neurons [62].

\section{Clinical trials}

An extended pilot study on transplanting native neuronal tissue into HD patients was conducted by Bachoud-Levi at the Henri Mondor hospital in Creteil France and associated centers in Europe. The cells were obtained from a 8-9 week aborted fetus. A single striatal ganglion was recovered and the cells placed into culture. Neuroblasts and neural precursors from these cultures were implanted into both striatal lobes of 5 patients in 2001. Assessment was done annually using a unified Huntington's disease rating scale (UHDRS), plus neuropsychological tests, MRI examination and positron-emission topography (PET). Three of five patients showed motor and cognitive improvements and recovery of metabolic function that reached a plateau after 2 years. Two of the patients showed no improvement and continued to decline. After 4 to 6 years, the recovered patients also began to decline. Dystonia continued to deteriorate but chorea did not and cognitive performance remained stable [63]. Another pilot study in 2001 and followed up 6 years later was conducted in Italy by Gallina et al. [64]. Whole ganglion eminences were harvested directly from the striatum of human fetuses (9-12 week) and then engrafted directly into the caudate head and putamen (striatum) of four HD patients. Stereotactic surgery was successful with no side-effects. Each patient received bilateral implants of ganglia derived from two fetal donors. After 4 months and up to 9 months, MRIs indicated that new striatal-like structures had formed, neuroblast proliferation took place in 6 of 8 grafts and all patients showed stabilization or improvement using UHDRS neurological indices. Furthermore, some of the neuroblasts were associated with the frontal cortex from the 4th to the 9 month suggesting possible migration. The test extended over a period of 18 to 34 months. Further studies for clinical efficacy are necessary, particularly to verify cell migration. Details of neural brain cell transplantation into HD patients have been reported in 2010 on six separate trials, including the above pilot test [65]. In summary, operatively, from 3 to 7 patients received neural implants into the brain striatum. The tissues were from fetal brain ganglionic tissue taken from fetuses aged 7.5 to 12 weeks. The clinical trials extended from 6 to 60 months. Analysis of the results included MRI images of the grafts that ranged from none to a visualization of the graft targets. The metabolic activity measured by PET varied from no change to an increase in some early HD patients up to 6 years post-operation. Impact on the UHDRS scores ranged from stabilization to a clinical improvement lasting up to 4 to 6 years after surgery. Some form of immuno-suppression was administered in each of the above studies. One or more suppressive agents (cyclosporine, prednisolone, azathioprine) were administered from 6 months up to 6 years after implantation. An assessment of neural transplants and many other variables including tissue source and processing, dosage, site and methods of delivery was made. Immuno-suppression seems to be a common denominator. While neural cell transplantation has the potential for treating and improving HD, the use of other cell transplants such as neuroblasts may be useful. As more is learned about the factors that cause this disease, ultimately recovery of autologous neurons, genetic modification in vitro, and re-inoculation would be the long range goal, particularly in view of the limited availability of human fetal tissues.

\section{Future prospects}

In the past 15 years there has been a concerted effort in animal models of Huntington disease on the use of neural stem cells, progenitor cells and immortalized cell lines to ultimately substitute for the use of primary fetal (human) tissues for treatment. A detailed review in 2007 [66] on the use of neural stem cells and progenitor stem cells to repair damaged regions of the striatum established that these cells can survive, integrate into the host animal brain and lead to some functional repair. A recent experiment [67] showed that adult neural progenitors cells of the rat can survive transplantation into the striatum of the brain and differentiate in vivo into astrocytes or mature neurons in a rat model of Huntington disease. These cells expressed markers of striatal neurons and resulted in a reduction of motor function impairment. The specific aims of human stem cell therapy have focused on identifying the most reliable cell precursors to replace the damaged neurons, or to provide neuroprotection to the endogenous neurons. There are promising new developments in the use of MSCs for neuroprotection of existing damaged neurons in animal models of $\mathrm{HD}$ by introducing specific factors. Some of these include brain derived neurotrophic factor (BDNF), (ciliary neurotrophic factor $\mathrm{CNF}$ ) and glial cell derived neurotrophic factor (GDNF). MSCs can be genetically altered and have been shown to be safe and reliable cells for the secretion of endogenous factors and the in vivo delivery of transgene products in animal models of disease including HD [68]. In both human HD patients and transgenic mice models there is found increased amounts of quinolinic acid (QA), an endogenous metabolite of tryptophan that is accompanied by a loss of gabanergic spinal neurons. A protocol for converting MSCs into neurotrophic factor (NTF) secretory cells was developed to treat striatal lesions in a rat model for HD [69]. The ability of MSCs to migrate toward damaged areas was veted by labeling the stem cells with micrometer magnetic particles and MRI confirmed that they migrated toward the lesion by 19 days. Another approach has been to use MSCs to reduce the effects of the toxic huntingtin RNA and the cell protein that leads to the death of spiny neurons. A number of laboratories have been studying interference RNA (siRNA) in murine models of HD and they have found that siRNA decreases mutant protein expression and does not affect normal proteins in spiny neurons [47]. Recently it has been reported by Olson that an anti-mutant siRNA for HTT has been produced and incorporated into human MSCs. (Amer. Acad. Neuroscience Annual Meeting, Honolulu HI, 2011). Preliminary reports cite that the MSCs can deliver the molecules into neurons in vitro and reduce the toxic htt proteins. The technique for the sustained delivery of the carrier MSCs has been formulated and a patent for the 
technique has been submitted [70]. The safety and efficacy of MSC transplants in humans is also being launched. A proposed human clinical trial (Phase I, safety) has been submitted to the NIH Clinical Trials in 2011 to evaluate the transfer of normal MSCs into the brains of HD patients (Bauer G, Holta J, Annett G. Stem cell infusion into brains of HD patients 201l).

\section{Parkinson Disease (PD)}

A chronic and progressive neurological disease affecting overall neuron motor control is the result of a gradual loss of dopaminergic neurons but other non-dopaminergic neurons can also be affected. Early symptoms are seen in tremor of the hands, arms, legs, jaw and face, slowness of movement (bradykinesia), rigidity of the limbs and trunk, then impaired balance and coordination. Later, difficulty in walking, talking and completion of simple tasks occur. Gradually control of general body functions, eating, etc., sleep disorders and depression follow ( Nat. Instit. Neurol.Disor. and Stroke, N.I.H. Information page). PD is the result of dopamine neurons dying in the ganglionic nucleus located in the midbrain, the substantia nigra and a decrease in the level of dopamine that affect the motor controls of the cells in the striatum. A neuropathological sign of Parkinson's disease of the appearance of Lewy bodies in the substantia nigra. They also appear in fetal grafts into the brains of PD patients after many years and underline the complexity of this disease [71]. A conventional drug for treatment is L-Dopa (levadopa) a precursor of dopamine [72]. Other drugs are used to replace or enhance dopamine but they eventually have side effects such as dyskinesia (involuntary movements) or gradually loss in drug response Another therapy is deep brain stimulation (DBS), or ablative surgery of the thalamus, pallidium and more recently, by bilateral subthalamic nucleus (DBS) done sequentially. These therapeutic approaches partially reduce the symptoms but often have side effects and they do not affect the progression of the disease. (Amer. Parkinson's. Disease. Assoc.Wash, 2002).

\section{Cell Replacement Therapy}

The improvements in clinical therapy for PS have resulted from the use of various tissue and cell sources for the treatment of PD. An in depth analysis for the present and future human clinical therapy for PD is contained in an extensive review by Anisimov [73]. The salient animal studies indicated that embryonic, fetal or neonatal transplants of neural tissues obtained from the substantia nigra region into the brain were more successful than those from adults. The dopaminergic neurons could repopulate the striatum, increase DA release and improve motor responses. Transplants of fetal mesencephalic tissues in clinical patients gave similar results but various ethical (use and availability of aborted embryos) and logistic factors apply. Since only $3 \%$ of the implanted neurons survive, that impacts the enormous number of grafted dopaminergic neurons needed, plus differences in cell handling and processing, variations in neurosurgical techniques and delivery of the cells to the appropriate brain sites, differences in patient selection, side effects of dyskinesia (both DA and graft induced) and immunosuppression are among the many variables. Following two large clinical trials involving transplantation of human fetal dopaminergic neurons that led to minimal improvements in young patients, it was concluded that these procedures cannot be recommended as a treatment for PD. Alternate sources for dopaminergic neurons include both adult and fetal adrenal medullary tissue but the results have been inconclusive with no long term effects for humans. More promising results have come from the transplant of human sympathetic neurons. The use of autologous carotid body cell implants into the brain of PD patients appear to convert exogenous L-DOPA to DA and encourage its storage but the trials have been non-uniform. The use of porcine fetal neuronal cells for xenogenic transplants has been successful in animals but results are variable in humans, require massive immuno-suppression or genetic modification and have safety issues from transmission of infectious diseases [73].

\section{Clinical trials}

A variety of human cells have been investigated as a source of dopamine producing cells either for direct cell replacement, functional rescue (neuroprotection) or enhancement of endogenous dopa cells. The first group are embryonic brain derived cells from the mesencephalon. Embryonic human brain cells as a source of dopamine neurons were transplanted into 40 patients of all ages and survived in $85 \%$ of the patients with some improvement in younger patients but none in older individuals [74]. Two other potential stem cell sources, neural progenitor stem cells (NPCs) and adult NSC cells have been enlisted but both require in vitro cultivation for differentiation into dopaminergic neurons and the yield is low. Improvement of the yield occurs with the addition of the glial neurotrophic factor but requires further genetic manipulation. The direct isolation of a patient's own neural stem cells for the autologous transplantation of the cells into the patient's brain was conducted by Levesque [75]. The neural stem cells were expanded in culture for several months and exposed to epigenetic factors at which time $15 \%$ of the cells were dopamine producers. Clinical scores (UPDRS) had improved by $83 \%$ after one year being off medication and motor scores had increased by $88 \%$ with improvements in rigidity, bradykinesia and control of tremors. At five years postoperatively the motor scores had returned to baseline levels. As of 2011 the same researchers are conducting a clinical study for the detection and recovery of neural stem cells from Parkinson's patients who are undergoing neurosurgical procedures [48]. The immediate projected use of such cells are for studies of the disease and drug testing.

\section{Other Stem Cell Sources of Dopamine Neurons}

Attempts to produce neural dopamine producing cells depend on other stem cell sources. Two major types are adult (HSC) stem cells and adult mesenchymal (MSC) (stromal) stem cells. The usual source of these stem cells are the bone marrow but similar stem cells have been obtained from a variety of peri-natal tissues: amnion, placenta, umbilical cord blood and Wharton's jelly and mobilized peripheral blood. Studies on bone marrow derived MSC cells in mice showed that they can synthesize and release L-Dopa, induce behavioral improvement and even migrate toward the substantia nigra. They are potentially a source of autologous derived multipotent stem cells for the derivation of neural cells in vitro. There is an essential need for "experimental studies utilizing human MSCs derived dopaminergic cells" [73]. Currently there are two trials using stromal cells for transplantation or infusion of PD patients. An ongoing study at the Jaslok Hospital and Research Center in Mumbai India and directed by P. Doshi involves the transplantation of autologous bone marrow derived MSC cells. They are stereo-tactically implanted into the striatum of the brain with the aim of developing dopamine secreting neural cells. Another procedure will utilize harvesting and implantation of autologous derived stem cells from adipose tissue. It is being conducted by Morales and Zuniga at the Instituto de Medicina Regenerativa in Tijuana, Mexico. The trail plans to process the stromal cells and deliver them via a catheter into the vertebral artery and intravenously [48].

\section{Embryonic Stem Cells}

Embryonic human hES cells are capable of being expanded in vitro 
and then differentiated into transplantable hNPCs or dopaminergic neurons [73]. Experiments in the mouse and in primates have indicated the ES derived cells can be implanted, become part of the neural system and reduce PD in model animals. Without prior differentiation into dopaminergic neurons, there are the formation of overgrowths at the transplantation site. Thus far, hES derived dopaminergic neurons have failed because of low survival rate and graft site proliferation of teratomas or terato-carcinomas. Until this is resolved, clinical trails with hES cells in humans cannot proceed safely.

\section{Induced Pluripotent Stem Cells}

Previous preclinical studies in the rat indicated that iPSC from reprogrammed fibroblasts could be incorporated into the fetal brain and improve motor neuron improvement in rats with simulated Parkinson's disease [76]. Subsequently, human neuronal cells were induced directly from human embryonic pluripotent stem cells (hES) and from human induced pluripotent (iPS) cells with four transcription factors, Brn2, Ascl1, Myt1l and Neuro D1. In addition they converted fetal and postnatal fibroblasts into neural (iN) cells. Inefficient cell generation and maturation require future studies before clinical application [77]. Another study [78] utilized three transcription factors: Mash 1, Nurr 1 and Lmxla to directly create functional dopaminergic neurons from mouse or human fibroblasts. Human fibroblasts were obtained from prenatal and adult donors of normal and Parkinson's patients but with very low efficiency. Thus far, iPSC induced cells have not been successfully employed clinically for treatment of Parkinson's disease. One factor has been that human iPSCs derived from hemangioblasts appear to be qualitatively inferior to hESC derived hemangioblasts and in addition the former cells exhibit early cell senescence [79].

\section{Probing Endogenous Dopaminergic Stem Cells}

The neurotrophic glial cell derived factor (GDNF) has been shown to alter the motor function and offer some protection to endogenous dopaminergic neurons [80]. Consequently there have been numerous clinical trials on the affect of GDNF in PD human patients by Gill et al. [81] in England and by Slevin [82]. The method of choice has been continuous infusion into the putamen region of the brain. There was an increase in dopa uptake and clinical improvement in motor responses and $63 \%$ improvements of UPDRS measured activities during the treatment. Such benefits were lost 9 to 12 months after cessation of treatment in the latter study.

\section{Discussion}

Thus far the stem cell application of clinical therapy trials for neurodegenerative diseases has progressed after the direct engraftment of human precursor fetal brain (ganglion) cells in Huntington disease. The use of indigenous bone marrow derived HSC, CD34 stem cells and MSC stem cells have demonstrated progress in the treatment of MS, ALS and Parkinson disease. Embryonic human brain cells as precursors to dopamine neurons have been probed. Autologous adult neural stem cells and adult neurons have also been transplanted in PD patients. Recently human fetal brain (progenitor) neural stem cells capable of differentiating into specialized neurons have been tested in PD patients. With continued pre-clinical research, further prospects using induced pluripotent stem cells will likely be implemented. The controversy involving the potential differentiation of MSCs into neurons need to be resolved. In addition to the examples cited earlier $[12-14,16]$ the use of MSC based therapy that resulted in significant improvements in PD behavior has been described extensively and could be an effective source of neurons, including dopaminergic neurons.
Experiments using human MSCs need to establish them as a reliable alternate source of human neurons [75]. One such study by Fu et al [83] on the conversion of human umbilical cord derived MSCs into dopaminergic neurons in vitro is a start. Given the known potential of MSCs cited in previous studies, i.e., regulation of inflammation, trophic stimulation of neuronal growth and the ability to introduce specific growth factors with their demonstrated neuroprotection in human patients, it may be revealing if future studies combined both MSCs and NSCs in clinical trials on HD and other diseases. Both endogenous and introduced neural cells could complement the therapy. These stem cells could possibly be administered in sequence, MSCs followed by NSCs or in combination in view of the transient nature of the MSC stimulus. A future step in MS therapy proposes to stimulate the recruitment of endogenous neuronal and glial cells in the adult brain and spinal cord and direct them to the damaged area where they could produce new neurons and glial cells [27]. Several animal studies have focused on adult neurogenesis, the potential induction of new endogenous NSCs in the brain, and these results have been inconclusive. Anisimov concluded that the use of human NPCs and NSCs are best served for studies on differentiation/cell survival and phenotypic stability of stem cells [75]. Many preclinical studies on animals and humans are needed to establish in vivo stem cell maturation, implement remyelination and effect directed migration. A consensus of the STEMS group is that the next phase of stem cell therapy for MS should be the promotion of remyelination by endogenous stem cells [49]. One such factor that inhibits oligodendrocyte progenitor maturation is hyaluronan which is a by-product of de-myelination [84]. The utilization of endogenous NSCs for the treatment of neurological diseases still requires more preclinical studies on how to activate and guide migration of NSCs in situ, trigger their proliferation and control their differentiation into specific neuronal types (neuronal or glial progenitors). Much might also be learned from the extensive studies in the mouse on how signaling pathways determine neural crest stem cell (NCSC) migration during normal development into sensory neurons and glial cells as they migrate during neurogenesis of the peripheral nervous system. Some NCSC are multipotent and their cell potential is the result of environmental cues [85]. Many cell surface and ECM elements have been identified as positive (thrombospondin, neuregulin, versican) or inhibitory (T-cahedrin, proteoglycans, glycoproteins) that contribute to NCSC guidance [86]. The gap between clinical progress reports and the potential use, particularly of drug components by the medical clinical and research community appears to be overly protracted. This has been addressed recently by Andrew Grove [87] at least for the efficacy of new drugs. He proposes continuing safety Phase I trials under the U.S. Food and Drug administration but efficacy trials would be established through input from qualified physicians. Patient responses to drug would be reported to a national data base, along with patient medical histories, all protected by biometric identifiers and open to all qualified researchers. The responses of patients to a drug or treatment would be monitored and compared to others in the database and instantly available to researchers and clinicians. The same paradigm could be extended to the selection, recovery and use of diverse stem cell sources as therapy protocols for treatment of neurodegenerative diseases.

\section{References}

1. George Q. Daley, David T. Scadden (2008) Prospects for stem cell-based therapy. Cell 132: $544-548$.

2. Ozolek JA, Jane EP, Esplen JE, Petrosko P, Wehn AK, et al. (2010) In vitro neural differentiation of human embryonic stem cells using a low-density mouse embryonic fibroblast feeder protocol. Methods Mol Biol 584: 71-95.

3. Maric D, Barker JL (2005) Fluorescence-based sorting of neural stem cells and progenitors. Curr Protoc Neurosci Chapter 3: Unit 3. 
4. Thompson JA, Itskovitz-Eldor J, Shapiro SS, Waknitz MA, Swiergief JJ, et al. (1998) Embryonic stem cell lines derived from human blastocysts. Science 282: $1145-1147$

5. Tweedell KS (2008) New paths to pluripotent stem cells. Curr Stem Cell Res Ther 3: 151-162.

6. Genbacev O, Krtolica A, Zdravkovic T, Brunette E, Powell S, et al. (2005) Serum-free derivation of human embryonic stem cell lines on human placental fibroblast feeders. Fertil Steril 83: 1517-1529.

7. Chung Y, Klimanskaya I, Becker S, Li T, Maserati M, et al. (2008) Human embryonic stem cell lines generated without embryo destruction. Cell Stem Cell 2: 113-117.

8. Ilic D, Giritharan G, Zdravkovic T, Caceres E, Genbacev O, et al. (2009) Derivation of human embryonic stem cell lines from biopsied blastomeres on human feeders with minimal exposure to xenomaterials. Stem Cells Dev 18: 1343-1350.

9. Kaiser J (2011) Embryonic stem cells. NIH wins suit challenging legality of research. Science 333: 683 .

10. Uccelli A, Moretta L, Pistoia V (2008) Mesenchymal stem cells in health and disease. Nat Rev Immunol 8: 726-736.

11. Tweedell KS (2004) Embryos, clones, and stem cells: a scientific primer. ScientificWorldJournal 4: 662-715.

12. Sanchez-Ramos J, Songa S, Cardozo-Pelaez F, Hazzi C, Stedeford T et al. (2000) Adult bone marrow stromal cells differentiate into neural cells in vitro. Exp Neurol 164: 247-256.

13. Mezey E, Key S, Vogelsang G, Szalayova I, Lange GD, et al. (2003) Transplanted bone marrow generates new neurons in human brains. Proc Nat Acad Sci USA 100: 1364-1369.

14. Sostak P, Theil D, Stepp H, Roeber S, Kretzschmar HA, et al. (2007) Detection of bone marrow-derived cells expressing a neural phenotype in the human brain. J Neuropathol Exp Neurol 66: 110-116.

15. Hardy SA, Maltman DJ, Przyborski SA (2008) Mesenchymal stem cells as mediators of neural differentiation. Curr Stem Cell Res Ther 3: 43-52.

16. Sigurjonsson OE, Perreault MC, Egeland T, Glover JC (2005) Adult human hematopoietic stem cells produce neurons efficiently in the regenerating chicken embryo spinal cord. Proc Natl Acad Sci U S A 102: 5227-5232.

17. Revazova ES, Turovets NA, Kochetkova OD, Agapova LS, Sebastian JL, et al. (2008) HLA homozygous stem cell lines derived from human parthenogenetic blastocysts. Cloning and Stem Cells 10: 11-14

18. Takahashi K, Yamanaka S (2006) Induction of pluripotent stem cells from mouse embryonic and adult fibroblast cultures by defined factors. Cell 126 $663-76$.

19. Takahashi K, Tanabe K, Ohnuki M, Megumi N, Ichisaka T et al. (2007) Induction of pluripotent stem cells from adult human fibroblasts by defined factors. Cell 131: 861-872.

20. Park I-H, Zhao R, West JA, Yabuuchi A, Huo H, et al. (2008) Reprogramming of human somatic cells to pluripotency with defined factors. Nature 451: 141-147.

21. Yu J, Hu K, Smuga-Otto K, Tian S, Stewart R, et al. (2009) Human induced pluripotent stem cells free of vector and transgene sequences. Science 324 : 797-801

22. de Souza N (2010) Primer: induced pluripotency. Nat Methods 7: 20-21.

23. Warren L, Manos PD, Ahfeldt T, Loh YH, Li H, et al. (2010) Highly efficient reprogramming to pluripotency and directed differentiation of human cells with synthetic modified mRNA. Cell Stem Cell 7: 618-630.

24. Yakubov E, Rechavi AG, Rosenblatt S, Givol D (2010) Reprogramming of human fibroblasts to pluripotent stem cells using mRNA of four transcription factors. Res Comm 394: 189-193.

25. Vierbuchen T, Ostermeier A, Pang ZP, Kokubu Y, Sudhof TC, et al. (2010) Direct conversion of fibroblasts to functional neurons by defined factors. Nature 463: 1035-1041.

26. Pang ZP, Yang N, Vierbuchen T, Ostermeier A, Fuentes DR, et al. (2011) Induction of human neuronal cells by defined transcription factors. Nature 476 : 220-223.

27. Lindvall O, Kokaia Z (2006) Stem cells for the treatment of neurological disorders. Nature 441: 1094-1096.
28. Smukler SR, Runciman SB, Xu S, van der Kooy D (2006) Embryonic stem cells assume a primitive neural stem cell fate in the absence of extrinsic influences. J Cell Biol 172: 79-90.

29. Nat R, Nilbratt M, Narkilahti S, Bengt W, Horvatta O, et al. (2007) Neurogenic neuroepithelial and radial glial cells generated from six human embryonic stem cell lines in serum-free suspension and adherent cultures Glia 55: 385- 399

30. HSU YC, Lee DC, Chiu IM (2007) Neural stem cells, neural progenitors and neurotrophic factors Cell Transplan. 16: 133-150

31. Vescovi AL, Parati EA, Gritti A, Powlin P, Ferrario M, et al. (1999) Isolation and cloning of multipotential stem cells from the embryonic human CNS and establishment of transplantable human neural stem cell lines by epigenetic stimulation. Exper Neurol 156: 71-83.

32. Ronaghi M, Erceg S, Stojkovic M, Moreno-Manzano V (2010) Challenge of stem cell therapy for spinal cord injury: Human embryonic stem cells endogenous neural stem cells, or induced pluripotent stem cells? Stem Cells 28: 93-99

33. Patel M, Yang S. (2010) Advances in reprogramming somatic cells to induced pluripotent stem cells. Stem Cell Rev. 6: 367-380.

34. Zwaka TP (2010) Stem cells: Troublesome memories. Nature 467: 280-281.

35. Amabile GA, Meissner A (2009) Induced pluripotent stem cells: curren progress and potential for regenerative medicine Trends. Mol Med 15: 59-68.

36. Hu BY, Weick JP, Yu J, Ma LX, Zhang XQ, et al. (2010) Neural differentiation of human induced pluripotent stem cells follows developmental principles but with variable potency. Proc Natl Acad Sci U S A 107: 4335-4340.

37. Kiskinis E, Eggan K (2010) Progress toward the clinical application of patientspecific pluripotent stem cells. J Clin Invest 120: 51-59.

38. Sipp D (2010) Challenges in the clinical application of induced pluripotent stem cells. Stem Cell Res Ther 1: 9-11.

39. Hayden EC (2011) Stem cells: The growing pains of pluripotency. Nature 473 $272-274$.

40. Mummery C (2011) Induced pluripotent stem cells--a cautionary note. N Engl J Med 364: 2160-2162.

41. Zhao T, Zhang ZN, Rong Z, Xu Y (2011) Immunogenicity of induced pluripotent stem cells. Nature 474: 212-215.

42. Apostolou E, Hochedlinger K (2011) Stem cells: iPS cells under attack. Nature 474: 165-166.

43. Ebert AD, Yu J, Rose FF Jr, Mattis VB, Lorson CL, et al. (2009) Induced pluripotent stem cells from a spinal muscular atrophy patient. Nature 457: 277 280.

44. Soldner F, Hockemeyer D, Beard C, Gao Q, Bell GW, et al. (2009) Parkinson's disease patient-derived induced pluripotent stem cells free of viral reprogramming factors. Cell 136: 964-977.

45. Miller ED, Li K, Kanade T, Weiss LE, Walker LM, et al. (2011) Spatially directed guidance of stem cell population migration by immobilized patterns of growth factors. Biomaterials 32: 2775-2785.

46. Hartman NW, Carpentino JE, LaMonica K, Mor DE, Naegele JR, et al. (2010) CXCL12-mediated guidance of migrating embryonic stem cell-derived neural progenitors transplanted into the hippocampus. PLoS One 5: e15856.

47. Joyce, N, Annett GA, Wirthlin L, Olson S, Bauer G, et al. (2010) Mesenchyma stem cells for the treatment of neurodegenerative disease. Regen Med 5: 933 946

48. Registry of Clinical Trials, U.S. National Institutes of Health (2011) http:// ClinicalTrials.gov

49. Martino G, Franklin RJ, Van Evercooren AB, Kerr DA; Stem Cells in Multiple Sclerosis (STEMS) Consensus Group (2010) Stem cell transplantation in multiple sclerosis: current status and future prospects. Nat Rev Neurol 6: 247 255.

50. Openshaw H, Nash RA, McSweeney PA (2002) High-dose immunosuppression and hematopoietic stem cell transplantation in autoimmune disease: clinical review. Biol Blood Marrow Transplant 8: 233-248.

51. Riordan NH, Ichim TE, Min WP, Wang H, Solano F, et al. (2009) Non-expanded adipose stromal vascular fraction cell therapy for multiple sclerosis. J Trans Med 7: 29. 
Citation: Tweedell KS (2011) Extrapolating Stem Cell Potential into Therapy: Current Parameters for Treating Neurological Defects. J Bioengineer \& Biomedical Sci S2:004. doi:10.4172/2155-9538.S2-004

Page 12 of 12

52. Karussis D, Karageorgiou C, Vaknin-Dembinsky A, Gowda-Kurkalli B, Gomori JM, et al. (2010) Safety and immunological effects of mesenchymal stem cell transplantation in patients with multiple sclerosis and amyotrophic lateral sclerosis. Arch Neurol 67: 1187-1194.

53. Connick P, Kolappan M, Patani R, Scott MA, Crawley C, et al. (2011) The mesenchymal stem cells in multiple sclerosis (MSCIMS) trial protocol and baseline cohort characteristics: an open-label pre-test: post-test study with blinded outcome assessments. Trials 12: 62 .

54. Nash RA, Bowen JD, McSweeney PA, Pavletic SZ, Maravilla KR, et al. (2003) High-dose immunosuppressive therapy and therapy and autologous peripheral blood stem cells transplantation for severe multiples sclerosis. Blood 102 2364-2372.

55. Burt RK, Loh Y, Cohen B, Stefoski D, Balabanov R, et al. (2009) Autologous non-myeloablative haemopoietic stem cell transplantation in relapsing-remitting multiple sclerosis: a phase I/II study. Lancet Neurol 8: 244-253.

56. Yamanaka K, Chun SJ, Boillee S, Fujimori-Tonou N, Yamashita H, et al. (2008) Astrocytes as determinants of disease progression in inherited amyotrophic lateral sclerosis. Nat Neurosci 11: 251-253.

57. Dunckley T, Huentelman MJ, Craig DW, Pearson JV, Szelinger S, et al. (2007) Whole-genome analysis of sporadic amyotrophic lateral sclerosis. $\mathrm{N}$ Engl $\mathrm{J}$ Med 357: 775-788.

58. DeJesus-Hernandez M, Mackenzie IR, Boeve BF, Boxer AL, Baker M, et al. (2011) Expanded GGGGCC hexanucleotide repeat in noncoding region of C9ORF72 causes chromosome 9p-linked FTD and ALS. Neuron 72: 245-256.

59. Dimos JT, Rodolfa KT, Niakan KK, Weisenthal LM, Mitsumoto H, et al. (2008) Induced pluripotent stem cells generated from patients with ALS can be differentiated into motor neurons. Science 321: 1218-1221.

60. Mazzini L, Ferrero I, Luparello V, Rustichelli D, Gunetti M, et al. (2010) Mesenchymal stem cell transplantation in amyotrophic lateral sclerosis: A phase I clinical trial. Exp Neurol 223: 229-237.

61. Kelley CM, Dunnett SB, Rosser AE (2009) Medium spiny neurons for transplantation in Huntington's disease. Biochem Soc Trans 37: 323-328.

62. Clelland CD, Barker RA, Watts C (2008) Cell therapy in Huntington disease Neurosurg Focus 24: E9.

63. Bachoud-Lévi AC, Gaura V, Brugières $P$, Lefaucheur JP, Boissé MF, et al. (2006) Effect of fetal neural transplants in patients with Huntington's disease 6 years after surgery: a long-term follow-up study. Lancet Neurol 5: 303-309.

64. Gallina P, Paganini M, Lombardini L, Mascalchi M, Porfirio B, et al. (2010) Human striatal neuroblasts develop and build a striatal-like structure into the brain of Huntington's disease patients after transplantation. Exp Neurol 222: 30-41.

65. Barker RA, Swain RA (2010) Neural transplantation for the treatment of Huntington's disease. European Neurol Rev 5: 41-45.

66. Dennett SB, Rosser AE (2007) Stem cell transplantation for Huntington's disease. Exp Neurol 203: 279-292.

67. Vazey EM, Chen K, Hughes SM, Connor B (2006) Transplanted adult neura progenitor cells survive, differentiate and reduce motor function impairment in a rodent model of Huntington's disease. Exp Neurol 199: 384-396.

68. Meyerrose T, Olson S, Pontow S, Kalomoiris S, Jung Y, et al. (2010) Mesenchymal stem cells for the sustained in vivo delivery of bioactive factors. Adv Drug Deliv Rev 62: 1167-1174.

69. Sadan O, Shemesh N, Barzilay R, Bahat-Stromza M, Melamed E, et al. (2008) Migration of neurotrophic factors-secreting mesenchymal stem cells toward a quinolinic acid lesion as viewed by magnetic resonance imaging. Stem Cells 26: $2542-2551$

70. O Ison S, Wirthlin L, Nolta J (2009) Human mesenchymal stem cells for the use of sustained delivery of anti-mutant $\mathrm{HttS}$ siRNA. Patent pending

71. Brudin P, Barker RA, Parmar M (2010) Chap 14. Neural grafting in Parkinson's disease: Problems and possibilities. Prog Brain Res 184: 265-294.

72. Freed CR (2002) Will embryonic stem cells be a useful source of dopamine neurons for transplant into patients with Parkinson's disease? Proc Natl Acad Sci U S A 99: 1755-1757

73. Anisimov SV (2009) Cell-based therapeutic approaches for Parkinson's disease: progress and perspectives. Rev Neurosci 20: 347-381.

74. Fred CR, Greene PE, Breeze RE, Tsai WY, DuMouchel W, et al. (2001) Transplantation of embryonic dopamine neurons for severe Parkinson's disease. New Eng J Med 344: 710-719.

75. Levesque MF, Neuman T, Rezak M (2009) Therapeutic microinjection of autologous adult human neural stem cells and differentiated neurons for Parkinson's disease: Five-year post-operative outcome. The Open Stem Cell J 1: $20-29$

76. Wernig M, Zhao JP, Pruszak J, Hedlund E, Fu D, et al. (2008) Neurons derived from reprogrammed fibroblasts functionally integrate into the fetal brain and improve symptoms of rats with Parkinson's disease. Proc Natl Acad Sci USA 105: 5856-5861.

77. Pang ZP, Yang N, Vierbuchen T, Osteremeier A, Fuentes DR, et al. (2011) Induction of human neuronal cells by defined transcription factors. Nature 476 : 220-223.

78. Caiazzo M, Dell'Anno MT, Dvoretskova E. Lazarevic D, Taverna S, et al. (2011) Direct generation of functional dopaminergic neurons from mouse and human fibroblasts. Nature 476: 224-227.

79. Allan LE, Petit GH, Brundin P (2010) Cell transplantation in Parkinson's disease: problems and perspectives. Curr Opin Neurol 23: 426-432.

80. Björklund A, Rosenblad C, Winkler C, Kirik D (1997) Studies on neuroprotective and regenerative effects of GDNF in a partial lesion model of Parkinson's disease. Neurobiol Dis 4: 186-200.

81. Patel NK, Bunnage M, Plaha P, Svendsen CN, Heywood P, et al. (2005) Intraputamenal infusion of glial cell line-derived neurotrophic factor in PD: two-year outcome study. Ann Neurol 57: 298-302.

82. Slevin JT, Gash DM, Smith CD, Gerhardt GA, Kryscio R, et al. (2007) Unilatera intraputamenal glial cell line-derived neurotrophic factor in patients with Parkinson disease: response to 1 year of treatment and 1 year of withdrawal. $J$ Neurosurg 106: 614-620.

83. Fu YS, Cheng YC, Lin MY, Cheng H, Chu PM, et al. (2006) Conversion of human umbilical cord mesenchymal stem cells in Wharton's jelly to dopaminergic neurons in vitro: potential therapeutic application for Parkinsonism. Stem Cells 24: $115-124$

84. Back SA, Tuohy TM, Chen H, Wallingford N, Craig A, et al. (2005) Hyaluronan accumulates in demyelinated lesions and inhibits oligodendrocyte progenito maturation. Nat Med 11: 966-972.

85. Mundell NA, Labosky PA (2011) Neural crest stem cell multipotency requires Foxd3 to maintain neural potential and repress mesenchymal fates. Development 138: 641-652.

86. Gammill LS, Roffers-Agarwal J (2010) Division of labor during trunk neura crest development. Dev Biol 344: 555-565.

87. Grove A (2011) Rethinking clinical trials. Science 334: 555-565. 